\title{
Factors associated with alcohol consumption and prescribed drugs with addiction potential among older women and men - the Nord-Trøndelag health study (HUNT2 and HUNT3), Norway, a population-based longitudinal study
}

Kjerstin Tevik ${ }^{1,2^{*}}$ (D) Geir Selbæk ${ }^{1,3,4}$, Knut Engedal ${ }^{1,5}$, Arnfinn Seim², Steinar Krokstad ${ }^{6,7}$ and Anne-S Helvik ${ }^{1,2,8}$

\begin{abstract}
Background: Little is known about factors associated with alcohol consumption and use of drugs with addiction potential in older adults. The aim of this study was to explore the association between socio-demographic variables, physical and mental health and the later (11 years) use of frequent drinking, prescribed drugs with addiction potential and the possible combination of frequent drinking and being prescribed drugs with addiction potential in older adults ( $\geq 65$ years).

Methods: In this longitudinal study, we used data from two surveys of the Nord-Trøndelag Health Study (HUNT2 1995-1997 and HUNT3 2006-2008), a population based study in Norway. We totally included 10,656 individuals (5683 women) aged 54 years and older when they participated in HUNT2. Frequent drinking was defined as drinking alcohol 4 days or more per week. Data on prescribed drugs with addiction potential were drawn from the Norwegian Prescription Database. Drugs with addiction potential were defined as at least one prescription of benzodiazepines, z-hypnotics or opioids during one year for a minimum of two consecutive years between 2005 and 2009.

Results: The typical frequent drinker in HUNT3 was younger, more educated, lived in urban areas, and reported smoking and drinking frequently in HUNT2 compared to the non-frequent drinker in HUNT3. The typical user of prescribed drugs with addiction potential in HUNT3 was an older woman who smoked and was in poor health, suffered from anxiety, had been hospitalized in the last 5 years and used anxiety or sleep medication every week or more often in HUNT2. The typical individual in HUNT3 with the possible combination of frequent drinking and being prescribed drugs with addiction potential had more education, smoked, drank frequently and used anxiety or sleep medication in HUNT2.

\footnotetext{
* Correspondence: kjtev@online.no

${ }^{1}$ Norwegian National Advisory Unit on Ageing and Health, Vestfold Hospital Trust, Tønsberg, Norway

${ }^{2}$ General Practice Research Unit, Department of Public Health and Nursing, Faculty of Medicine and Health Sciences, Norwegian University of Science and Technology (NTNU), Trondheim, Norway

Full list of author information is available at the end of the article
}

(c) The Author(s). 2019 Open Access This article is distributed under the terms of the Creative Commons Attribution 4.0 International License (http://creativecommons.org/licenses/by/4.0/), which permits unrestricted use, distribution, and reproduction in any medium, provided you give appropriate credit to the original author(s) and the source, provide a link to the Creative Commons license, and indicate if changes were made. The Creative Commons Public Domain Dedication waiver (http://creativecommons.org/publicdomain/zero/1.0/) applies to the data made available in this article, unless otherwise stated. 
(Continued from previous page)

Conclusion: Individuals who were identified as frequent drinkers in HUNT2 were more likely to be frequent drinkers in HUNT3, and to have the possible combination of frequent drinking and being prescribed drugs with addiction potential in HUNT3. Health care professionals need to be aware of use of alcohol among older adults using drugs with addiction potential.

Keywords: Addictive drugs, Ageing, Alcohol, Elderly, Drinkers, Drinking, HUNT, Longitudinal study, Psychotropic drugs, Substance misuse

\section{Background}

Older adults often consume less alcohol than their younger peers [1], but alcohol consumption, both in quantity and frequency, has increased in recent decades among older adults in Nordic [2-4] and European countries [57] and in the USA $[8,9]$. This is of concern, as heavy alcohol consumption is harmful [10-14] and older adults are more susceptible to the side effects of alcohol because of age-related changes in metabolism and body composition $[12,15]$. In the coming decades, the number of older adults will grow, increasing the likelihood that the number of older adults with problematic alcohol consumption will increase as well [16]. Knowing which factors are associated with frequent alcohol consumption in old age can help identify older adults that might be at higher risk of this problem.

A large number of studies have shown that alcohol consumption in older adults is associated with men [9, 17$22]$, younger age $[9,17,20-22]$, current smoking $[9,17-$ 21 ] and past smoking [17-19], higher socio-economic status (i.e. more education, income and social status) [7, 9, $17,18,21,22]$, friends' approval of drinking [23], living in an urban setting [17], better health status [9, 18-20, 22, 24] and less cognitive impairment [20]. Some studies have found having a co-habitant $[17,19,22,24]$ is associated with alcohol consumption in older adults, while other studies have found not having a co-habitant $[9,18,25,26]$ is associated with alcohol consumption among older adults. Moreover, there is conflicting evidence regarding an association between alcohol consumption and depression in older adults [9, 20, 27].

With a few exceptions [23, 26], studies of factors associated with alcohol consumption in older adults have a cross-sectional design [7, 9, 17-22, 24, 25, 27]. This makes it difficult to draw conclusions about causality related to the importance of socio-demographic, physical and mental health factors for alcohol consumption [28].

Drugs with addiction potential are used frequently among older adults in Western countries [28-31]. This is of concern because the use of drugs with addiction potential is associated with adverse health consequences [32-34]. In the present study, we use the term "drugs with addiction potential" to describe the use of benzodiazepines (hypnotics/sedative or anxiolytics), z-hypnotics or opioids, and the term "addictive psychotropic drugs" to describe benzodiazepines (hypnotics/ sedatives or anxiolytics) and z-hypnotics.

The use of addictive psychotropic drugs in older adults has been associated with higher age $[18,19,30,35]$, women [7, 18, 19, 30, 35-39], smoking [19, 35], living alone [18], lower education and lower social status [7, 19], but the findings regarding gender and living alone is somewhat conflicting [35, 40]. Use of addictive psychotropic drugs in older adults has been related to psychiatric condition in general $[35,37]$ and to specific diseases such as depression $[35,39,40]$, anxiety [39], dementia [40] and sleep disorders [35, 39, 40]. These drugs has also been associated with poorer health status [7, 18, 19, 35, 39], comorbidity [36, 37, 41], higher levels of self-reported pain and stress [37] and more medical consultations [41]. In older adults, the use of opioids is more likely in older individuals [18], among women [18, 19], in those with worse health status [7, 18, 19], lower social status [7, 19] and those using multiple medications (polypharmacy) [18]. Several studies investigating factors associated with use of drugs with addiction potential have had a longitudinal design [7, 35-37, 39, 40], which allows us to draw conclusions with greater certainty regarding causality of factors associated with use of drugs with addiction potential.

There is concern about the combined use of alcohol and drugs with addiction potential in older adults [12, $29,38]$. Older adults are more susceptible to side effects from this combined use due to age-related changes in the absorption, distribution and metabolism of alcohol and drugs with addiction potential [12]. Individuals may experience effects from the interaction between alcohol and drugs with addiction potential even at light to moderate drinking levels (e.g. 1-2 drinks per occasion) [12]. The combined use of these drugs and alcohol may cause side effects such as increased sedation, memory problems, impaired coordination and breathing difficulties, which in turn can result in a higher risk of falls, injuries, accidents and even death [12, 18, 29, 38, 42].

Cross-sectional studies have identified older age [18], men [38], poorer health status [19], living in rural areas 
[18], living alone [18], higher social status [18], polypharmacy $[18,19]$ and poor social network [18] as contributing factors to the possible combination of frequent drinking and use of drugs with addiction potential among older adults.

Nevertheless, little is known about factors associated with frequent alcohol consumption and/or use of drugs with addiction potential in older adults in Norway [30, 43-46] or internationally [9, 16, 19, 40, 41]. A better understanding of these factors can help health personnel identify older adults who may be at higher risk for this use. The aim of this study is to explore the association between socio-demographic variables, physical and mental health and the later use ( 11 years) of frequent drinking, prescribed drugs with addiction potential and the possible combination of frequent drinking and use of these drugs in older men and women.

\section{Methods}

\section{Study setting, data sources and participants}

The Nord-Trøndelag Health Study (HUNT) [47] is based in Nord-Trøndelag County in mid-Norway [48, 49]. In 2006, the county had 128,649 residents, approximately $97 \%$ of whom were Caucasian [48, 49]. The population of Nord-Trøndelag County is fairly representative of Norway's total population in terms of age and gender distribution, mortality and health status $[48,50]$. The mean income and prevalence of more years of education in inhabitants, and the prevalence of current smokers are all slightly lower in Nord-Trøndelag compared to the whole of Norway [48]. The county also does not contain any large cities $[48,51]$.

Three HUNT Surveys have been completed to date: HUNT1 in 1984-1986, HUNT2 in 1995-1997 and HUNT3 in 2006-2008 [49]. All county residents 20 years or older have been invited to participate in the surveys [49].

We used data from HUNT2 and HUNT3 in this study. Individuals who were invited to participate in HUNT2 were also invited to participate in HUNT3 roughly 11 years later. Table 1 describes the total participation rates for HUNT2 and HUNT3, and for individuals aged 50 years and older. A non-participation study showed only minor potential non-participation bias after HUNT2, while non-participants in HUNT3 had lower socioeconomic status, poorer health, and a higher prevalence of chronic diseases and mental distress than those who participated [50]. Additional information on the HUNT studies has been provided elsewhere [48, 49].

In our study, we included 10,656 participants aged 54 years and above from HUNT2 who had answered the first questionnaire in HUNT2 and the required question about alcohol consumption in HUNT3. Totally, 400 participants who responded to the alcohol frequency question in HUNT2, did not respond to this question in HUNT3, and thus excluded from the study. Very few participants who were 80 years or older in HUNT2 participated in HUNT3 (see Table 1). As they did not differ compared to those 79 years or younger in HUNT2 regarding frequent drinking or the possible combination of frequent drinking and use of drugs with addiction potential in HUNT3, they were included in our analyses. Due to missing information on individual independent variables in HUNT2, the number of participants varied from 10,656 to 6320 in our analyses.

Information about the use of drugs with addiction potential was drawn from the Norwegian Prescription Database (NorPD) [52] of the Norwegian Institute of Public Health from 2005 to 2009 and was linked to HUNT2 and HUNT3 participants. The NorPD contains data about dispensed drugs beginning in 2004 for all citizens in Norway [52].

\section{Measures}

Alcohol consumption in HUNT2 and HUNT3

The drinking frequency measures in HUNT2 and HUNT3 differed slightly. In HUNT2, participants were asked how many times a month they drank alcohol, while participants in HUNT3 were asked how often during the last 12 months they drank alcohol. The response options in HUNT3 were: $1=4-7$ times a week, $2=2-3$ times a week, $3=$ about once a week, $4=2-3$ times a month, $5=$ about once a month, $6=$ a few times a year, $7=$ not at all the last year and $8=$ never drink alcohol. As drinking frequency was a categorical variable it was dichotomized in order to distinguish between those with high drinking frequency and those with lower drinking frequency or non-drinking. We defined drinking "4-7 times a week" as the equivalent of consuming alcohol 4 days or more per week in HUNT3 (alcohol consumption $\geq 4$ days/week $=$ frequent drinking/frequent drinkers). Our study considered drinking 16 times or more per month as the equivalent of consuming alcohol 4 days or more per week in HUNT2.

\section{Drugs with addiction potential in HUNT2 and HUNT3}

In HUNT2, participants self-reported use of prescribed drugs with addiction potential. They were asked to report how often they had taken anxiolytic or sleep medication in the last month, with the following response options: 1 = daily, 2 = weekly, but not every day, $3=$ not as often as every week and $4=$ never. Our study merged response categories 1 and 2 under the description of daily or weekly use of anxiolytic or sleep medication.

In the HUNT3 sample, information drawn from the NorPD (2005-2009) about prescribed drugs with addiction potential [52] was categorized according to the Anatomical Therapeutic Classification system (ATC) [53]. Drugs with addiction potential were defined as prescribed benzodiazepines (BZD), z-hypnotics or opioids. 
Table 1 Participation in HUNT2 (1995-1997) and HUNT3 (2006-2008) Survey

\begin{tabular}{|c|c|c|c|}
\hline \multirow[t]{2}{*}{ HUNT2 } & Invited & \multicolumn{2}{|c|}{ Participated in HUNT2 } \\
\hline & $\mathrm{N}$ & N & $\%$ \\
\hline Total $^{\mathrm{a}}$ & 93,898 & 65,237 & 69.5 \\
\hline \multicolumn{4}{|l|}{$A g e^{b}$} \\
\hline $50-59$ & $13,831^{b}$ & 11,205 & 81.2 \\
\hline $60-69$ & 10,655 & 9089 & 85.6 \\
\hline 70-79 & 10,510 & 8310 & 79.9 \\
\hline $80-89$ & 5413 & 3202 & 66.0 \\
\hline $90+$ & 906 & 387 & 52.9 \\
\hline \multirow[t]{2}{*}{ HUNT3 } & Invited & \multicolumn{2}{|c|}{ Participated in HUNT3 } \\
\hline & $\mathrm{N}$ & N & $\%$ \\
\hline Total $^{\mathrm{a}}$ & 93,860 & 50,807 & 54.1 \\
\hline \multicolumn{4}{|l|}{$\mathrm{Age}^{\mathrm{a}}$} \\
\hline $50-59$ & 17,313 & 11,409 & 65.9 \\
\hline $60-69$ & 13,801 & 9811 & 71.1 \\
\hline 70-79 & 8594 & 5744 & 66.8 \\
\hline $80-89$ & 5496 & 2287 & 41.6 \\
\hline $90+$ & 890 & 153 & 17.2 \\
\hline \multirow[t]{2}{*}{ Age at participation in HUNT2 } & Could have participated ${ }^{c}$ in HUNT3 & \multicolumn{2}{|c|}{ Participated in both HUNT2 and HUNT3 } \\
\hline & N & N & $\%$ \\
\hline Total $^{a}$ & 65,237 & 37,071 & 56.8 \\
\hline \multicolumn{4}{|l|}{$\mathrm{Age}^{\mathrm{a}}$} \\
\hline $50-59$ & 11,060 & 8195 & 74.1 \\
\hline $60-69$ & 9049 & 5049 & 55.8 \\
\hline $70-79$ & 7994 & 1800 & 22.5 \\
\hline $80-89$ & 2621 & 84 & 3.2 \\
\hline $90+$ & 162 & 0 & 0 \\
\hline
\end{tabular}

${ }^{a}$ Reference: Krokstad et al. [49]

${ }^{b}$ Reference: Holmen et al. [48]

'Could have participated: Includes those who participated in HUNT3, those who did not participate in HUNT3, those who were not invited (deceased, emigrated or disappeared), or moved out of the county

BZD were categorized under ATC codes N03AE (antiepileptic), N05BA (anxiolytic) and N05CD (hypnotic and sedative) [53]. Z-hypnotics were categorized under ATC code N05CF [53] and opioids under ATC code N02A [53]. In order to distinguish between use of drugs with addiction potential versus no use, the prescription of drugs with addiction potential was categorized as a dichotomized variable. The use of prescribed drugs with addiction potential was defined as at least one prescription of BZD, z-hypnotics or opioids within one year in a minimum of two consecutive years (2005/2006, 2006/ $2007,2007 / 2008$ or $2008 / 2009$ ) [54, 55] which means that the drugs were prescribed at the same time as HUNT3 was completed.

To enable comparisons between prescribed drugs in HUNT2 and HUNT3, we defined a subgroup of addictive psychotropic drugs in HUNT3 as prescribed BZD or z-hypnotics.

\section{Possible combination of use of alcohol and prescribed drugs with addiction potential in HUNT3}

The possible combination of use of alcohol and prescribed drugs with addiction potential was defined as frequent drinking in HUNT3 and being prescribed drugs with addiction potential at the same time as HUNT3 was completed.

\section{Independent variables from HUNT2}

Smoking status in HUNT2 was assessed using three categories; $1=$ never smoked daily, 2 = previously smoked daily and $3=$ daily smoker. 
Self-reported health status was assessed by one question with four response alternatives. Due to the response distribution, the variable was dichotomized to very good/good and poor/not so good health status.

Hospitalization during the last 5 years (yes/no) and history of medical diagnoses (myocardial infarction, angina, stroke/brain haemorrhage, diabetes, hyperthyroidism, hypothyroidism, osteoporosis, fibromyalgia, rheumatoid arthritis, epilepsy and asthma) were assessed by self-reported questions in HUNT2.

Anxiety and depression were self-reported by the Hospital Anxiety and Depression Scale (HADS) [56]. Seven items assess anxiety symptoms (HAD-A), and seven items assess depressive symptoms (HAD-D). Each item is scored $0-3$, and the sum-score is from 0 to 21 on each subscale. A sum-score $\geq 8$ on HAD-A and HAD-D indicates clinically significant anxiety (HAD-A) and depression (HAD-D), respectively [57]. The HADS has been validated in older adults [58] and in a general population [59] in Norway and the psychometric properties are $\operatorname{good}[58,59]$.

Overall life satisfaction was assessed by one question with seven response categories ranging from 1 (very satisfied) to 7 (very dissatisfied). Due to the response distribution, the variable was dichotomized to "satisfied" (response option 1-3) and "dissatisfied/neither satisfied nor dissatisfied" (4-7).

Socio-demographic variables.

The socio-economic variables were gender, age at the time of survey completion, level of education (up to ten years of education, vocational and general education, college and university), urban versus rural living and marital status (living spouse or partner versus not). Age was further categorised into three groups (54-59 years, $60-64$ years and 65 years or older).

\section{Ethics and data protection}

All participants signed an informed and written consent allowing use of their data for future medical research $[48,49]$ and allowing their data to be linked to other health records [48]. The linkage is possible due to the unique 11-digit personal identification number all Norwegians have [48]. In our study, the Norwegian Institute of Public Health linked data from HUNT2, HUNT3 and the NorPD, and only anonymous data were handed over for research due to Norwegian regulations.

The Regional Committee of Medical Research Ethics (REC) (reference number 2014/1248), the Norwegian Data Inspectorate Authority, the Norwegian Social Science Data Services (project number 40081), the Norwegian Data Inspectorate Authority (reference number 14/ 01248-2EOL) and the Norwegian Institute of Public Health have all approved the present study.

\section{Statistics}

The data was analysed with SPSS version 23. Descriptive analysis of categorical variables was performed using Chi-Square test.

We used McNemar's Exact Test to investigate the change in drinking frequency ( $\geq 4$ days/week) from HUNT2 to HUNT3 and the change in use of prescribed drugs; i.e. self-reported use of anxiolytic or sleep medication in HUNT2 to prescribed addictive psychotropic drugs in HUNT3.

Logistic regression analysis (the "enter" method) was used to examine the association between independent variables assessed in HUNT2 and three dependent variables assessed in HUNT3: Outcomes 1) frequent drinking (alcohol consumption $\geq 4$ days/week) (versus not), 2) prescribed drugs with addiction potential (versus not), and 3) the possible combination of frequent drinking and being prescribed drugs with addiction potential (versus no frequent drinking, no use of drugs with addiction potential or neither frequent drinking nor being prescribed drugs with addiction potential). The independent variables (HUNT2) included in the unadjusted analyses were gender (women reference category), age (54-59 years reference category), level of education (up to ten years education reference category), living in urban versus rural areas, marital status (no living spouse or partner reference category), smoking status (never smoked daily reference category), overall health status (poor/not so good reference category), hospitalized during the last 5 years (versus not), HADS anxiety sum score $\geq 8$ (versus $<8$ ), HADS depression sum score $\geq 8$ (versus $<8$ ), overall life satisfaction (dissatisfied/neither satisfied nor dissatisfied reference category), frequent drinking (alcohol consumption $\geq 4$ days/week) (versus alcohol consumption < 4 days/week) and self-reported use of anxiolytic and sleep medication every week or more (versus not). In the adjusted analyses, gender and age and other covariates associated with the outcome $(p \leq 0.1)$ in the unadjusted analyses were included.

The participants included in the assessment of outcome 3 (possible combined use of frequent drinking and use of drugs with addiction potential) were drawn from those included in outcome 1 (frequent drinking) and outcome 2 (drugs with addiction potential).

Statistical tests were carried out to assess for interactions between gender and other covariates. We did not find any interactions. Unadjusted and adjusted analyses were presented with odds ratios (OR) and 95\% confidence intervals $(\mathrm{CI})$. Probability values below 0.05 were considered statistically significant.

\section{Results}

Table 2 shows the basic characteristics of HUNT2 participants $(N=10,656)$. The participants' mean age was 
Table 2 Sample characteristics for the HUNT2 sample. The HUNT Study 1995-1997 (HUNT2) and 2006-2008 (HUNT3)

\begin{tabular}{|c|c|c|c|c|c|}
\hline \multirow[t]{2}{*}{ HUNT2 } & & \multirow{2}{*}{$\begin{array}{l}\text { All participants } \\
\text { Overall }\end{array}$} & \multirow{2}{*}{$\begin{array}{l}\text { HUNT3 } \\
\text { Frequent drinking: } \\
\text { alcohol consumption } \\
\geq 4 \text { days/week) }{ }^{\mathrm{a}}\end{array}$} & \multirow{2}{*}{$\begin{array}{l}\text { HUNT3 } \\
\text { Prescribed drugs with } \\
\text { addiction potential }^{b}\end{array}$} & \multirow{2}{*}{$\begin{array}{l}\text { HUNT3 } \\
\text { Possible combination of frequent drinking } \\
\text { (alcohol consumption } \geq 4 \text { days/week) and } \\
\text { being prescribed drugs with addiction potential }\end{array}$} \\
\hline & & & & & \\
\hline Overall & $N(\%)$ & $10,656(100)$ & $323(3.0)$ & $3444(32.3)$ & $107(1.0)$ \\
\hline \multicolumn{6}{|l|}{ Gender } \\
\hline Women & N (\%) & $5683(53.3)$ & $114(35.3)^{\mathrm{d}^{* * *}}$ & $2325(67.5)^{\mathrm{e}^{* * * *}}$ & $51(47.7)^{\mathrm{fNS}}$ \\
\hline \multicolumn{6}{|l|}{ Age } \\
\hline $53-59$ years & N (\%) & $4318(40.5)$ & $134(41.5)^{\mathrm{d}^{*}}$ & $1096(31.8)^{\mathrm{e}^{* * *}}$ & $48(44.9)^{\mathrm{fNS}}$ \\
\hline 60-64 years & N (\%) & $2677(25.1)$ & $93(28.8)$ & $838(24.3)$ & $21(19.6)$ \\
\hline $65+$ & N (\%) & $3661(34.4)$ & $96(29.7)$ & $1510(43.8)$ & $38(35.5)$ \\
\hline \multicolumn{6}{|l|}{ Level of educationc } \\
\hline Up to ten years education & N (\%) & $8421(83.1)$ & $166(52.4)^{\mathrm{d}^{* * *}}$ & $2800(86.3)^{\mathrm{e}^{* * *}}$ & $61(59.2)^{\mathrm{f} * * *}$ \\
\hline $\begin{array}{l}\text { Vocational and general } \\
\text { education }\end{array}$ & N (\%) & $255(2.5)$ & $23(7.2)$ & $73(2.3)$ & $6(5.8)$ \\
\hline College and university & N (\%) & $1454(14.4)$ & $128(40.4)$ & $371(11.4)$ & $36(35.0)$ \\
\hline \multicolumn{6}{|l|}{ Living in } \\
\hline Rural areas & N (\%) & $4141(38.9)$ & $79(24.5)^{d^{* * *}}$ & $1414(41.1)^{\mathrm{e}^{* * *}}$ & $31(29.0)^{\mathrm{fNS}}$ \\
\hline Urban areas & N (\%) & $6515(61.1)$ & $244(75.5)$ & $2030(58.9)$ & $76(71.0)$ \\
\hline \multicolumn{6}{|l|}{ Marital status ${ }^{c}$} \\
\hline No living spouse or partner & N (\%) & $2223(20.9)$ & $53(16.4)^{\mathrm{d}^{*}}$ & $828(24.1)^{\mathrm{e}^{* * *}}$ & $26(24.3)^{\mathrm{fNS}}$ \\
\hline Living spouse or partner & N (\%) & $8420(79.1)$ & $270(83.6)$ & $2611(75.9)$ & $81(75.7)$ \\
\hline \multicolumn{6}{|l|}{ Smoking status ${ }^{c}$} \\
\hline Never smoked daily & N (\%) & 4607 (43.6) & $81(25.2)^{\mathrm{d}^{* * *}}$ & $1425(41.9)^{\mathrm{e}^{* * *}}$ & $26(24.5)^{p * * *}$ \\
\hline Former daily smoker & N (\%) & $3772(35.7)$ & $162(50.3)$ & $1141(33.6)$ & $50(47.2)$ \\
\hline Daily smoker & N (\%) & $2177(20.7)$ & $79(24.5)$ & $832(24.5)$ & $30(28.3)$ \\
\hline \multicolumn{6}{|l|}{ Overall health status ${ }^{c}$} \\
\hline Poor/not quite good & N (\%) & $3624(34.3)$ & $84(26.2)^{\mathrm{d}^{* *}}$ & $1580(46.2)^{e^{* * *}}$ & $43(40.2)^{\mathrm{fNS}}$ \\
\hline Good/very good & N (\%) & $6940(65.7)$ & $237(73.8)$ & $1838(53.8)$ & $64(59.8)$ \\
\hline $\begin{array}{l}\text { Hospitalized during the last } 5 \\
\text { years }^{c}\end{array}$ & N (\%) & $3051(33.2)$ & $92(32.4)^{\mathrm{dNS}}$ & $1144(38.5)^{\mathrm{e}^{* * * *}}$ & $36(38.3)^{\mathrm{fNS}}$ \\
\hline HADS anxiety score $\geq 8^{c}$ & N (\%) & $1091(12.9)$ & $30(10.8)^{\mathrm{dNS}}$ & $542(20.8)^{\mathrm{e}^{* * *}}$ & $15(17.4)^{\mathrm{fNS}}$ \\
\hline HADS depression score $\geq 8^{c}$ & N (\%) & $1166(12.1)$ & $29(9.6)^{d N S}$ & $494(16.0)^{\mathrm{e}^{* * *}}$ & $13(13.3)^{\mathrm{fNS}}$ \\
\hline \multicolumn{6}{|l|}{ Life satisfaction $^{c}$} \\
\hline $\begin{array}{l}\text { Dissatisfied/neither satisfied nor } \\
\text { dissatisfied }\end{array}$ & N (\%) & $1586(15.1)$ & $39(12.3)^{\mathrm{dNS}}$ & $668(19.7)^{\mathrm{e}^{* * *}}$ & $15(14.4)^{\mathrm{fNS}}$ \\
\hline Satisfied & N (\%) & 8904 (84.9) & $277(87.7)$ & 2716 (80.3) & 89 (85.6) \\
\hline
\end{tabular}

HADS Hospital Anxiety Depression scale, NS non-significant

a Self-reported alcohol consumption assessed among participants in HUNT3

${ }^{b}$ Information about prescribed drugs with addiction potential among participants in HUNT3 (2006-2008) was drawn from the Norwegian

Prescription Database. Drugs with addiction potential were defined as at least one prescription of benzodiazepines, z-hypnotics or opioids in two consecutive years (2005/2006, 2006/2007, 2007/2008 or 2008/2009). Benzodiazepines defined by N03AE, N05BA and N05CD. Z-hypnotics defined by N05CF. Opioids defined by N02A

${ }^{\mathrm{c}}$ Number do not sum up to 10,656 because of missing information

${ }^{d}$ Significance testing with Chi-square test between no frequent drinking (alcohol consumption $<4$ days/week) and frequent drinking (alcohol consumption $\geq 4$ days/week) (HUNT3)

${ }^{\mathrm{e}}$ Significance testing with Chi-square test between no prescribed drugs with addiction potential and prescribed drugs with addiction potential (HUNT3) fSignificance testing with Chi-square test between "no possible combination of frequent drinking (alcohol consumption $\geq 4$ days/week) and being prescribed drugs with addiction potential" and "possible combination of frequent drinking (alcohol consumption $\geq 4$ days/week) and being prescribed drugs with addiction potential" (HUNT3)

${ }^{*} P<0.05$

$* * P<0.01$

***P $P<0.001$ 
$62.7(\mathrm{SD}=6.4)$ and $53 \%$ were women. The prevalence of self-reported medical illness was $4.0 \%$ for myocardial infarction, $6.3 \%$ for angina pectoris, $1.7 \%$ for stroke/brain haemorrhage, $2.5 \%$ for hyperthyroidism, $4.3 \%$ for hypothyroidism, $4.0 \%$ for osteoporosis, $5.0 \%$ for fibromyalgia, $3.6 \%$ for rheumatoid arthritis and $8 \%$ for asthma.

\section{Frequent drinking in HUNT3}

In total, $3.0 \%(323 / 10,656)$ of older adults $(\geq 54$ years in HUNT2) were frequent drinkers (alcohol consumption $\geq 4$ days/week) when they participated in HUNT3 (Table 2). There was no association between any medical diagnosis in HUNT2 and frequent drinking in HUNT3, with the exception of rheumatoid arthritis. Participants in HUNT3 who were frequent drinkers (versus not), were less likely in HUNT2 to report rheumatoid arthritis (1.3\% versus $3.7 \%)$.

In total, $4.8 \%(400 / 8355)$ of the participants who responded to the alcohol frequency question in HUNT2, were excluded in HUNT3 since they did not respond to the alcohol frequency question in HUNT3 (Additional file 1: Table S1). Those excluded did not differ in frequency of drinking in HUNT2, but were older, more often women, lived without a spouse or partner, were non-smokers, had poor health status, had more anxiety and used anxiolytic or sleep medication in HUNT2 and had fewer years of education compared to those who responded to the alcohol frequency question in HUNT3.

Among participants who had answered the alcohol frequency question in HUNT2 and HUNT3, the prevalence of frequent drinking increased in the total sample from $1.0 \%$ in HUNT2 to $3.7 \%$ in HUNT3. Among women, this increase was from 0.4 to $2.7 \%$ while among men it was from 1.7 to $4.7 \%$ (Table 3).

Frequent drinkers in HUNT2 had about 33 times higher odds of being frequent drinkers in HUNT3 compared to non-frequent drinkers in HUNT2 (Table 4).

In adjusted logistic regression analyses, the typical frequent drinker in HUNT3 was younger, had more education, lived in urban areas, and smoked and drank frequently ( $\geq 4$ days/week) in HUNT2 compared to the non-frequent drinker in HUNT3 (Table 4). The explained adjusted variance assessed using Nagelkerke R-Squared was $17.3 \%$. Unadjusted results are shown in Additional file 2: Table S2.

\section{Drugs with addiction potential in HUNT3}

Nearly one-third $(3444 / 10,656=32.3 \%)$ of participants in HUNT3 were prescribed at least one drug with addiction potential (BZD, z-hypnotics or opioids) in two consecutive years (Table 2). About 10\% reported use of anxiolytic or sleep medication in HUNT2, and 27.1\% were prescribed addictive psychotropic drugs (BZD or z-hypnotics) in HUNT3 (Table 3).

Participants in HUNT3 who were prescribed drugs with addiction potential (versus not), were more likely in HUNT2 to report angina pectoris (8.0\% versus 5.5\%), stroke/brain haemorrhage (2.7\% versus $1.2 \%)$, hyperthyroidism ( $3.2 \%$ versus $2.2 \%$ ), hypothyroidism ( $5.7 \%$ versus $3.7 \%)$, osteoporosis $(6.5 \%$ versus $2.9 \%)$, fibromyalgia (9.4\% versus $3.1 \%)$, rheumatoid arthritis (5.3\% versus $2.9 \%$ ) and asthma (9.7\% versus $7.2 \%)$.

Users of anxiolytic or sleep medication in HUNT2 had more than five times higher odds of being prescribed drugs with addiction potential in HUNT3 compared to non-users of anxiolytic or sleep medication in HUNT2 (Table 4).

In adjusted logistic regression analyses, the typical user of prescribed drugs with addiction potential in HUNT3 was found to be an older woman who smoked and was in poor health, suffered from anxiety, had been hospitalized during the last 5 years and had reported use of anxiety or sleep medication every week or more in HUNT2 (Table 4). The explained adjusted variance assessed using Nagelkerke R-squared was 19.5\%. Unadjusted findings are presented in Additional file 2: Table S2.

\section{Possible combination of frequent drinking and being prescribed drugs with addiction potential in HUNT3}

One per cent of the HUNT3 study sample $(107 / 10,656)$ were frequent drinkers and had also been prescribed drugs with addiction potential during the same period that HUNT3 was completed (Table 2). With one exception, we found no association between any medical diagnosis in HUNT2 and the possible combination of frequent drinking and being prescribed drugs with addiction potential in HUNT3. The exception was that participants in HUNT3 with this possible combination (versus not), were more likely in HUNT2 to report angina pectoris (13.2\% versus $6.2 \%$ ).

Frequent drinkers in HUNT2 had about eight times higher odds of having the possible combination of frequent drinking and being prescribed drugs with addiction potential in HUNT3 compared to non-frequent drinkers in HUNT2 (Table 4). Users of anxiolytic or sleep medication in HUNT2 had about two times higher odds of having the possible combination of frequent drinking and being prescribed drugs with addiction potential in HUNT3 compared to non-users of anxiolytic or sleep medication in HUNT2 (Table 4).

In the adjusted logistic regression analyses, the typical individual with the possible combination of frequent drinking and being prescribed drugs with addiction potential in HUNT3 had more education, smoked, drank frequently and used anxiety or sleep medication in HUNT2 compared to the individual with no such use in 
Table 3 Use of alcohol and prescribed drugs in HUNT2 (1995-1997) and HUNT3 (2006-2008)

\begin{tabular}{|c|c|c|c|}
\hline & & \multicolumn{2}{|c|}{$\begin{array}{l}\text { Prevalence of frequent drinking (alcohol consumption } \geq 4 \text { days/week) among participants in HUNT2 } \\
\text { and who participated in HUNT3 } 11 \text { years later }\end{array}$} \\
\hline & & HUNT2 & HUNT3 \\
\hline Total $(n=7955)$ & N (\%) & $83(1.0)$ & $297(3.7)^{\mathrm{c}^{* * *}}$ \\
\hline \multicolumn{4}{|l|}{ Gender } \\
\hline Women $(n=3876)$ & N (\%) & $14(0.4)$ & $106(2.7)^{c^{* * *}}$ \\
\hline Men $(n=4079)$ & N (\%) & $69(1.7)$ & $191(4.7)^{\mathrm{c}^{* * *}}$ \\
\hline \multicolumn{4}{|l|}{ Age group in HUNT2: } \\
\hline $53-59$ years $(n=3462)$ & N (\%) & $30(0.9)$ & $150(4.3)^{\mathrm{c}^{* * * *}}$ \\
\hline $60-64$ years $(n=2020)$ & N (\%) & $20(1.0)$ & $71(3.5)^{\kappa^{* *}}$ \\
\hline \multirow[t]{3}{*}{$\geq 65$ years $(n=2473)$} & N (\%) & $33(1.3)$ & $76(3.1)^{\mathrm{c}^{*}}$ \\
\hline & & \multicolumn{2}{|c|}{$\begin{array}{l}\text { Prevalence of use of prescribed drugs among participants in } \mathrm{HUNT}^{\mathrm{a}} \text { and who participated in HUNT3 } \\
11 \text { years later }\end{array}$} \\
\hline & & HUNT2 & HUNT3 \\
\hline Total $(n=8691)$ & N (\%) & $858(9.9)$ & $2354(27.1)^{c^{* * *}}$ \\
\hline \multicolumn{4}{|l|}{ Gender } \\
\hline Female $(n=4714)$ & N (\%) & $621(13.2)$ & $1681(35.7)^{c^{* * *}}$ \\
\hline Male $(n=3977)$ & N (\%) & $237(6.0)$ & $673(16.9)^{)^{* * *}}$ \\
\hline \multicolumn{4}{|l|}{ Age group in HUNT2 } \\
\hline $53-59$ years $(n=3481)$ & N (\%) & $265(7.6)$ & $693(19.9)^{)^{* * *}}$ \\
\hline $60-64$ years $(n=2196)$ & N (\%) & $207(9.4)$ & $573(26.1)^{c^{* * *}}$ \\
\hline$\geq 65$ years $(n=3014)$ & N (\%) & $386(12.8)$ & $1088(36.1)^{c^{* * *}}$ \\
\hline
\end{tabular}

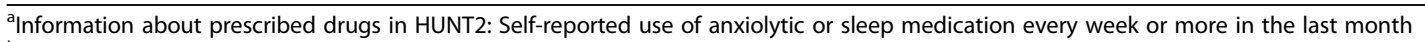

${ }^{b}$ Information about prescribed drugs in HUNT3: Addictive psychotropic drugs drawn from the Norwegian Prescription Database were defined as at least one prescription of benzodiazepines or z-hypnotics in two consecutive years (2005/2006, 2006/2007, 2007/2008 or 2008/2009). Benzodiazepines defined by N03AE, N05BA and N05CD. Z-hypnotics defined by N05CF

'Significance testing with McNemar's Exact Test

${ }^{* * *} P<0.001$

HUNT3 (Table 4). The explained adjusted variance assessed using Nagelkerke R-squared was 6.8\%. Unadjusted results are shown in Additional file 2: Table S2.

\section{Discussion}

This is the first large population-based study to explore factors associated with frequent drinking (alcohol consumption $\geq 4$ days/week) and being prescribed drugs with addiction potential (BZD, z-hypnotics or opioids) using a longitudinal design in older adults aged 65 years or more at follow-up.

In our study, the typical frequent drinker in HUNT3 was younger, had more years of education, lived in urban areas, and smoked and drank frequently ( $\geq 4$ days/week) in HUNT2 compared to the non-frequent drinker in HUNT3. The typical user of prescribed drugs with addiction potential in HUNT3 was found to be an older woman who smoked and was in poor health and suffered from anxiety, had been hospitalized in the last 5 years and used anxiety or sleep medication every week or more in HUNT2. The typical individual with the possible combination of frequent drinking and being prescribed drugs with addiction potential in HUNT3 had more education, smoked, drank frequently and used anxiety or sleep medication in HUNT2 compared to the individual with no such use in HUNT3 (see Table 5 which summarize the findings).

In our study, we found that those who were frequent drinkers ( $\geq 4$ days/week) in HUNT2 had about 33 times higher odds of being frequent drinkers when they participated in HUNT3. Furthermore, they had about eight times higher odds of having the possible combination of frequent drinking and being prescribed drugs with addiction potential in HUNT3. Thus, it seems that middle-aged drinkers continue their drinking pattern of frequent drinking as they age.

Since our definition of alcohol drinking only included frequency of alcohol consumption ( $\geq 4$ days/week), this definition may include participants with both risky drinking ( $\geq 7$ drinks in a week) and non-risky drinking ( $<7$ drinks in a week) [60]. Thus, it is uncertain if higher odds for later frequent drinking will increase the risk of alcohol-related problems in older adults [60]. However, a recently published meta-analysis, including all ages, found that the level of alcohol consumption that minimizes health loss is zero [14]. Moreover, a combination 
Table 4 Adjusted logistic regression analyses of alcohol consumption and use of drugs with addiction potential (HUNT3)

\begin{tabular}{|c|c|c|c|}
\hline \multirow[t]{5}{*}{ HUNT2 } & Outcome 1 (HUNT3): & Outcome 2 (HUNT3) & Outcome 3 (HUNT3): \\
\hline & Frequent drinking: & Prescribed drugs with & $\begin{array}{l}\text { Possible combination of frequent } \\
\text { drinking }\end{array}$ \\
\hline & alcohol consumption $\geq 4$ days/week ${ }^{\text {b }}$ & addiction potential $^{c}$ & $\begin{array}{l}\text { (alcohol consumption } \geq 4 \text { days/week) } \\
\text { and being prescribed } \\
\text { drugs with addiction potential }\end{array}$ \\
\hline & Adjusted $^{\mathrm{e}}$ & Adjusted $^{e}$ & Adjusted $^{e}$ \\
\hline & OR $95 \% \mathrm{Cl}$ & OR $95 \% \mathrm{Cl}$ & OR $95 \% \mathrm{Cl}$ \\
\hline Gender (men) & $1.22(0.93-1.60)$ & $0.45(0.40-0.51)$ & $0.77(0.48-1.25)$ \\
\hline \multicolumn{4}{|l|}{ Age } \\
\hline $54-59$ & 1 (ref. category) & 1 (ref. category) & 1 (ref. category) \\
\hline $60-64$ & $0.82(0.60-1.12)$ & $1.43(1.23-1.66)$ & $0.66(0.35-1.27)$ \\
\hline$\geq 65$ & $0.69(0.51-0.95)$ & $2.06(1.79-2.37)$ & $1.23(0.74-2.05)$ \\
\hline \multicolumn{4}{|l|}{ Level of education } \\
\hline Up to ten years education & 1 (ref. category) & 1 (ref. category) & 1 (ref. category) \\
\hline Vocational and general education & $2.84(1.63-4.95)$ & $0.89(0.62-1.27)$ & $1.23(0.36-4.19)$ \\
\hline College and university & $3.69(2.81-4.86)$ & $0.90(0.76-1.07)$ & $2.35(1.40-3.95)$ \\
\hline \multicolumn{4}{|l|}{ Living in } \\
\hline Rural areas & 1 (ref. category) & 1 (ref. category) & 1 (ref. category) \\
\hline Urban areas & $1.68(1.26-2.25)$ & $0.92(0.82-1.04)$ & $1.33(0.80-2.21)$ \\
\hline \multicolumn{4}{|l|}{ Marital status } \\
\hline No living spouse or partner & 1 (ref. category) & 1 (ref. category) & \\
\hline Living spouse or partner & $1.05(0.74-1.48)$ & $0.96(0.83-1.11)$ & \\
\hline \multicolumn{4}{|l|}{ Smoking status } \\
\hline Never smoked daily & 1 (ref. category) & 1 (ref. category) & 1 (ref. category) \\
\hline Former daily smoker & $1.95(1.43-2.65)$ & $1.28(1.11-1.46)$ & $2.25(1.25-4.06)$ \\
\hline Daily smoker & $1.49(1.04-2.16)$ & $1.69(1.44-1.98)$ & $1.98(1.01-3.88)$ \\
\hline \multicolumn{4}{|l|}{ Overall health status } \\
\hline Poor/not quite good & 1 (ref. category) & 1 (ref. category) & \\
\hline Good/very good & $1.07(0.80-1.42)$ & $0.64(0.56-0.73)$ & \\
\hline Hospitalized during the last 5 years & & $1.21(1.07-1.37)$ & \\
\hline \multicolumn{4}{|l|}{ HADS anxiety score } \\
\hline$<8$ & & 1 (ref. category) & \\
\hline$\geq 8$ & & $1.68(1.39-2.03)$ & \\
\hline \multicolumn{4}{|l|}{ HADS depression score } \\
\hline$<8$ & & 1 (ref. category) & \\
\hline$\geq 8$ & & $1.00(0.81-1.23)$ & \\
\hline \multicolumn{4}{|l|}{ Overall life satisfaction } \\
\hline Dissatisfied/neither satisfied nor dissatisfied & & 1 (ref. category) & \\
\hline Satisfied & & $1.02(0.84-1.23)$ & \\
\hline \multicolumn{4}{|l|}{ Alcohol consumption $^{d}$} \\
\hline$<4$ days/week & 1 (ref. category) & & 1 (ref. category) \\
\hline$\geq 4$ days/week & $33.32(20.09-55.25)$ & & $8.40(3.67-19.25)$ \\
\hline \multicolumn{4}{|c|}{ Use of anxiolytic or sleep medication every week or more ${ }^{d}$} \\
\hline No & & 1 (ref. category) & 1 (ref. category) \\
\hline Yes & & $5.67(4.56-7.05)$ & $2.25(1.23-4.12)$ \\
\hline
\end{tabular}


Table 4 Adjusted logistic regression analyses of alcohol consumption and use of drugs with addiction potential (HUNT3) (Continued)

\begin{tabular}{|c|c|c|c|}
\hline \multirow[t]{5}{*}{ HUNT2 } & Outcome 1 (HUNT3): & Outcome 2 (HUNT3): & Outcome 3 (HUNT3): \\
\hline & Frequent drinking: & Prescribed drugs with & $\begin{array}{l}\text { Possible combination of frequent } \\
\text { drinking }\end{array}$ \\
\hline & alcohol consumption $\geq 4$ days/week ${ }^{\text {b }}$ & addiction potential $^{c}$ & $\begin{array}{l}\text { (alcohol consumption } \geq 4 \text { days/week) } \\
\text { and being prescribed } \\
\text { drugs with addiction potential }\end{array}$ \\
\hline & Adjusted $^{e}$ & Adjusted $^{e}$ & Adjusted $^{e}$ \\
\hline & OR 95\% Cl & OR 95\% Cl & OR 95\% Cl \\
\hline$R^{2} \%^{f}$ & 17.3 & 19.5 & 6.8 \\
\hline
\end{tabular}

Bold numbers indicate significant associations. OR odds ratio, $\mathrm{Cl}$ confidence interval, HADS Hospital Anxiety and Depression scale

${ }^{a}$ Number of participants in the adjusted analyses with outcome 1 is $N=7541$, outcome $2 N=6277$ and outcome $3 N=6320$

belf-reported alcohol consumption assessed among participants in HUNT3 (2006-2008)

'Information on prescribed drugs with addiction potential among participants in HUNT3 (2006-2008) was drawn from the Norwegian Prescription Database. Drugs with addiction potential were defined as at least one prescription of benzodiazepines (BZD), z-hypnotics or opioids in two consecutive years (2005/2006, 2006/ $2007,2007 / 2008$ or 2008/2009). BZD defined by N03AE, N05BA and N05CD, z-hypnotics defined by N05CF and opioids by N02A

${ }^{\mathrm{d}}$ Self-reported use of alcohol in the last month and self-reported use of anxiolytic or sleep medication every week or more in the last month among participants in HUNT2

${ }^{\text {e}}$ Adjusted binary logistic regression analysis. Gender and age and other covariates associated with the outcome ( $\left.p \leq 0.1\right)$ in the unadjusted analyses (see Supplemental Table 2) were included in the adjusted analyses. Outcome 1: frequent drinking (alcohol consumption $\geq 4$ days/week) (alcohol consumption $<4$ days/ week reference category). Outcome 2: prescribed drugs with addiction potential (BZD, z-hypnotics or opioids) (no prescribed drugs with addiction potential reference category). Outcome 3: possible combination of frequent drinking (alcohol consumption $\geq 4$ days/week) and being prescribed drugs with addiction potential (BZD, z-hypnotics or opioids). Reference category: no frequent drinking, no use of drugs with addiction potential or neither frequent drinking - nor being prescribed drugs with addiction potential

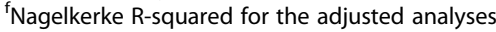

of frequent drinking and use of drugs with addiction potential is of concern as greater drinking frequency increases the risk of concomitant use of alcohol and drugs $[31,61]$. However, we do not know if these substances were used together in our study.

Though the majority of our sample were non-frequent drinkers (<4 days/week), our study has shown that drinking frequency $\geq 4$ days/week increased overall from HUNT2 to HUNT3, and in both genders. The increased number of healthy years experienced by older adults [6, 7], improved household finances [4], international travelling [4] and a more "continental" drinking pattern [43] might be reasons for the increase in drinking frequency among older adults in Norway. Even though the drinking pattern in HUNT2 of those not responding to the alcohol frequency question in HUNT3 (4.8\%) did not differ with those responding to this question in HUNT3, the increased prevalence of high drinking frequency in HUNT3 might be inflated by those excluded. Those excluded were older, more often women, had fewer years of education and poorer health status and may have stopped drinking. We do not know why they did not answer the question. It could be because it was not relevant to them, albeit the alcohol frequency question did allow for a non-drinking response.

Furthermore, we found that the reported use of anxiolytic and sleep medication in HUNT2 was associated with being prescribed drugs with addiction potential, and the possible combination of frequent drinking and being prescribed drugs with addiction potential in HUNT3. Other studies have found similar results, where previous use of addictive psychotropic drugs was highly

Table 5 Factors associated with frequent drinking and drugs with addiction potential ${ }^{\mathrm{a}}$. (HUNT2 1995-1997 and HUNT3 2006-2008)

\begin{tabular}{|c|c|c|}
\hline $\begin{array}{l}\text { Outcome } 1 \text { (HUNT3): Frequent } \\
\text { drinking ( } \geq 4 \text { days/week) }\end{array}$ & $\begin{array}{l}\text { Outcome } 2 \text { (HUNT3): Use of prescribed } \\
\text { drugs with addiction potential }\end{array}$ & $\begin{array}{l}\text { Outcome } 3 \text { (HUNT3): Possible combination of } \\
\text { frequent drinking ( } \geq 4 \text { days/week) and use of } \\
\text { prescribed drugs with addiction potential }\end{array}$ \\
\hline Factors assessed in HUNT2: & Factors assessed in HUNT2: & Factors assessed in HUNT2: \\
\hline - Younger age & • Women & - More years of education \\
\hline - More years of education & - Older age & - Daily smoker or former daily smoker \\
\hline - Living in urban areas & - Daily smoker or former daily smoker & \\
\hline - Daily smoker or former daily smoker & $\begin{array}{l}\text { - Poor health } \\
\text { - Anxiety }\end{array}$ & - Frequent drinking ( $\geq 4$ days/week) \\
\hline - Frequent drinking ( $\geq 4$ days/week) & $\begin{array}{l}\text { - Been hospitalized in the last } 5 \text { years } \\
\text { - Use of anxiolytic or sleep medication every week or more }\end{array}$ & $\begin{array}{l}\text { - Use of anxiolytic or sleep medication } \\
\text { every week or more }\end{array}$ \\
\hline
\end{tabular}


associated with subsequent use [37, 39]. Unfortunately, we do not know the indications for the prescriptions, the dosages or use between these two time points. Moreover, we found an increase in the use of addictive psychotropic drugs from HUNT2 (1995-1997) to HUNT3 (2006-2008). However, different methodology was used in defining use of drugs; i.e. self-reported use of anxiolytic and sleep medication in HUNT2 versus prescribed addictive psychotropic drugs among participants in HUNT3. Thus, due to the limitations pointed out we must be cautious in interpreting these results. The combined use of alcohol and drugs with addiction potential among older adults may be the result of using alcohol to self-medicate mental disorders and pain with alcohol, while taking drugs with addiction potential [29]. Nevertheless, we did not find an association between mental health (e.g. anxiety and depression) and the possible combination of frequent drinking and being prescribed drugs with addiction potential. Another explanation might be that older adults are unaware the potential harm of concomitant use [17, 62].

We also found that more men than women in HUNT3 were frequent drinkers, and more women than men were prescribed drugs with addiction potential. These findings are consistent with previous studies $[7,18,19$, 38]. Higher alcohol consumption among men than women in our study may be explained by social norms, cultural values, gender-specific roles in Norway and biological differences between men and women [4, 45]. A previous study showed that among participants 60 years and older in HUNT3, the prevalence of insomnia, musculoskeletal pain, osteoporosis, fibromyalgia and arthrosis was higher in women than men [50], and may explain why women were more likely to be prescribed drugs with addiction potential in our study. Another reason might be that women are much more likely than men to talk about their feelings and distress and to seek help for their health issues [63]. Physicians may also respond differently to mental health and pain problems among women and men [7, 64, 65] and therefore be more likely to prescribe drugs with addiction potential to women [7, 66]. Men might use alcohol to resolve problems with anxiety, depression, insomnia and pain, while women to a greater degree are prescribed drugs with addiction potential to treat these kinds of health problems $[63,66]$.

In line with previous studies, we found that the prevalence of frequent drinking ( $\geq 4$ days/week) decreased with increasing age $[19,31]$, while the prevalence of being prescribed drugs with addiction potential increased with increasing age $[18,19,30,35,36,40]$. The reasons why older adults decrease their alcohol consumption as they become older might be because of poorer health, decreased socialization, lower tolerance to alcohol and negative experiences with alcohol $[3,15,67]$, a birth cohort effect [3] where older cohorts are likely to drink less than the younger cohort (i.e. the baby boomers born after World War II) [15] and the mortality hypothesis, where those who drink more die at an earlier age due to health problems $[15,20,21,27]$. The prevalence of insomnia [68], comorbidities [42] and chronic pain [69] increases in older adults and may explain the higher odds of being prescribed drugs with addiction potential by increasing age. Another explanation might be that older adults' existential needs and mental health problems may be handled by prescribing addictive psychotropic drugs instead of alternative treatment options such as referral to psychotherapy $[70,71]$. General practitioners have also reported that it can be difficult to stop the prescription of addictive psychotropic drugs [71] and are likely to renew prescriptions without performing a drug review [72].

Consistent with other studies, more years of education $[17,18,21,22,45,46]$ and living in urban areas [73] were associated with frequent drinking in our study. More education and living in urban areas indicate higher socioeconomic status [45], and these older adults may better afford to buy alcohol. Social and cultural norms on drinking patterns, and alcohol availability, i.e. alcohol outlets, pubs and other places that serve alcoholic beverages, may also vary between urban and rural areas $[45,73]$.

Smokers had higher odds of consuming alcohol frequently, being prescribed drugs with addiction potential, and the possible combination of frequent drinking and use of prescribed drugs with addiction potential than non-smokers. This association has been observed in several previous studies, both for alcohol $[9,17-21,23]$ and for addictive psychotropic drugs [35, 39]. Few studies have investigated factors associated with the use of both alcohol and drugs with addiction potential [18, 19, 38], and none of them found an association between smoking and the possible combination of use of alcohol and drugs. Biological factors [74], genetic factors [74] and increased satisfaction and calming effects with combined use [75] may explain the co-use of alcohol and tobacco. Smokers have reported that nicotine reduces their symptoms of anxiety [76] and chronic pain [77] and might be reasons for the association between smoking and drugs with addiction potential in our study.

\section{Strengths and limitations}

This study has several strengths. Firstly, we have followed a large population cohort of community-dwelling adults in Nord-Trøndelag County in Norway [47]. Nord-Trøndelag County has a stable and homogenous population $[4,50]$, and the county is similar to the general population of Norway in many health aspects [48-50]. 
A second and major strength of our study is its longitudinal design, spanning more than a decade. This allowed us to investigate several factors potentially associated with the later use of alcohol and/or being prescribed drugs with addiction potential.

Thirdly, we used data from a nationwide prescription database [52] which gave us complete information on all prescriptions dispensed in Norwegian pharmacies during the observation period. This prevents selection bias and recall bias [78]. However, we do not know if the dispensed drugs were taken or the indication for use [78].

Despite the strengths of our study, it still has limitations that should be considered. Firstly, participants who responded to the alcohol frequency question in HUNT2, but not in HUNT3, were excluded from our study. Those excluded, as previously stated, may have quit drinking, and therefore the increased prevalence of frequent drinking in HUNT3 could be overestimated. Even so, a non-participation study conducted after HUNT3 [50] indicate on the other hand that those with the most serious addiction problems did not participate in HUNT3. Thus, it is likely that the prevalence of high drinking frequency and prescription of drugs with addiction potential in HUNT3 were underestimated.

As in other studies, self-report of alcohol consumption may contribute to less accurate estimates and an underestimation of alcohol consumption, and especially in heavy drinkers [20]. Further, the findings in our study represent patterns of alcohol use that are solely based on drinking frequency. We did not have information about how many drinks or units of alcohol the participants consumed the day they drank alcohol. It is therefore unclear if someone who drinks 4 days/week consumes more alcohol than someone who drinks 2 days/week. Moreover, since our definition of frequent drinking only included drinking alcohol 4 days or more a week, this definition may include participants with both risky drinking ( $\geq 7$ drinks/week) and non-risky drinking $(<7$ drinks/week) [60].

Variations in how questions about alcohol consumption were asked in HUNT2 and HUNT3 make it necessary to be cautious when interpreting results. In addition, it was not possible to determine whether alcohol and drugs with addiction potential were used simultaneously. Participants may not drink on the day they take the drug, and not all drugs are taken daily. An interaction can only occur if both alcohol and drugs are present in the body simultaneously [79].

Moreover, HUNT2 was conducted in 1995-1997 and HUNT3 in 2006-2008. Thus, a more current survey might have produced different data. The fourth health study in Nord-Trøndelag (HUNT4) (2017-2019) will give us new opportunities to investigate the trend in use of alcohol among older adults in Norway. In the present study we chose to focus on frequent alcohol consumption defined as drinking 4 days or more a week. It could also be of interest to study the trend of other frequency of alcohol consumption.

In addition, very few person 80 years or older in HUNT2 participated in HUNT3. These participants were kept in our analyses as they did not differ compared to those 79 years or younger regarding frequent drinking or the possible combination of frequent drinking and use of drugs with addiction potential.

Although we adjusted for various socio-demographic, physical and psychological health factors, the possibility of residual confounding cannot be ruled out [35]. In our logistic regression model, the $R$-squared $\left(R^{2}\right)$ for the outcome possible combination of frequent drinking and being prescribed drugs with addiction potential was very low $(6.8 \%)$. This indicates that other factors not included in our analyses have great importance for the association with the possible combination of use of alcohol and drugs with addiction potential. We did not have information about insomnia, pain, polypharmacy and loss of close family members and friends, all of which may be potential factors associated with higher use of alcohol and drugs with addiction potential in older adults $[18,19,28,35,36,39,40]$.

\section{Clinical implications}

Knowledge about factors associated with frequent alcohol consumption and drugs with addiction potential in older adults may help health personnel to identify subgroups at higher future risk [15]. To avoid potential interaction between alcohol and drugs with addiction potential, there is a need for health personnel to focus on asking older adults about their drinking behaviour and drug use [31]. However, prior evidence has shown that health personnel often do not have established routines for asking older patients about their alcohol consumption, or informing them about the health consequences of alcohol consumption at older age and the possible harmful interaction effect between alcohol and drugs $[67,70,71]$.

\section{Conclusion}

Individuals who were identified as frequent drinkers in HUNT2 were more likely to be frequent drinkers in HUNT3, and to have the possible combination of frequent drinking and being prescribed drugs with addiction potential in HUNT3.

Understanding factors associated with later use of frequent drinking and the possible combination of frequent drinking and use of prescribed drugs with addiction potential might contribute to increased awareness among health care personnel regarding older patients that could be at higher risk in the future. Health care professionals 
need to be aware of use of alcohol among older adults using drugs with addiction potential.

\section{Additional files}

Additional file 1: Table S1. Sample characteristic of participants in HUNT2 (1995-97) who responded versus did not respond to the alcohol frequency question in HUNT3 (2006-08) (DOCX $16 \mathrm{~kb}$ )

Additional file 2: Table S2. Unadjusted logistic regression analyses of alcohol consumption and use of prescribed drugs with addiction potential (HUNT3 2006-08). The table shows unadjusted odds ratio for the association between independent variables assessed in HUNT2 (1995-97) (sociodemographic variables, physical and mental health) and three dependent variables assessed in HUNT3 (2006-08): Outcomes 1) Frequent drinking (alcohol consumption $\geq 4$ days/week), 2) Prescribed drugs with addiction potential and 3) The possible combination of frequent drinking and being prescribed drugs with addiction potential. (DOCX $16 \mathrm{~kb}$ )

\section{Abbreviations}

ATC: Anatomical therapeutic classification system; BZD: Benzodiazepines; Cl: Confidence interval; HADS: Hospital Anxiety and Depression Scale; HUNT: The Nord-Trøndelag Health Study; HUNT2: The Nord-Trøndelag Health Study in 1995-1997; HUNT3: The Nord-Trøndelag Health Study in 2006-2008; NorPD: Norwegian Prescription Database; OR: Odds ratio

\section{Acknowledgments}

We thank all those who participated in the Nord-Trøndelag Health Study (The HUNT Study). The HUNT Study is a collaboration between the HUNT Research Centre (Faculty of Medicine and Health Sciences, Norwegian University of Science and Technology, NTNU), Nord-Trøndelag County Council, Central Norway Regional Health Authority and the Norwegian Institute of Public Health. The authors also wish to acknowledge the services of the Norwegian Prescription Database.

\section{Funding}

This project has been made possible by the Norwegian Extra Foundation for Health and Rehabilitation (https://www.extrastiftelsen.no/) through the Norwegian Council for Mental Health (http://www.psykiskhelse.no/) (2015/ FO5044). In addition, the project has been funded partly by the Norwegian National Advisory Unit on Ageing and Health, Vestfold Hospital Trust (http:// www.aldringoghelse.no/). KT is a PhD fellow in this project and she received the funding. The funders had no role in the study design, data collection and analyses, decision to publish, or preparation of the manuscript.

\section{Availability of data and materials}

The confidentiality requirements under Norwegian law and the informed consent of the participants' sets limits regarding storage of data from HUNT, so that data on individual level cannot be shared in public repositories. Researchers wishing to analyse data from the HUNT study for any reason may apply to the HUNT organization (http://www.ntnu.edu/hunt) to get access, after obtaining the permits needed under Norwegian law. Contact information is: HUNT Research Centre, Forskningsveien 2, N-7600 Levanger, email: hunt@medisin.ntnu.no.

\section{Authors' contributions}

$\mathrm{KT}$ analysed the data, and participated in interpreting results and drafting the manuscript. GS and KE participated in the study design, interpreting results and drafting the manuscript. AS and SK participated in interpreting results and drafting the manuscript. ASH had the main responsibility for the study design and participated in analysing the data, interpreting results and drafting the manuscript. All authors have read and approved the manuscript.

\section{Ethics approval and consent to participate}

Research in HUNT is carried out in accordance with the guidelines of the Regional Committee of Medical Research Ethics (REC), the Norwegian Data Inspectorate Authority and applicable law. REC (REC South-East D, reference number 2014/1248, dated 11.09.2014), the Norwegian Social Science Data Services (project number 40081), the Norwegian Data Inspectorate Authority (reference number 14/01248-2EOL, dated 22.01.2015) and the Norwegian Institute of Public Health have all approved the present study. All participants in HUNT provided written informed consent. No experimental interventions were performed.

\section{Consent for publication}

Not applicable

\section{Competing interests}

The authors declare that they have no competing interests.

\section{Publisher's Note}

Springer Nature remains neutral with regard to jurisdictional claims in published maps and institutional affiliations.

\section{Author details}

${ }^{1}$ Norwegian National Advisory Unit on Ageing and Health, Vestfold Hospital Trust, Tønsberg, Norway. ${ }^{2}$ General Practice Research Unit, Department of Public Health and Nursing, Faculty of Medicine and Health Sciences, Norwegian University of Science and Technology (NTNU), Trondheim, Norway. ${ }^{3}$ The Research Centre for Age-related Functional Decline and Disease, Innlandet Hospital Trust, Ottestad, Norway. ${ }^{4}$ Faculty of Medicine, Institute of Health and Society, University of Oslo, Oslo, Norway. ${ }^{5}$ Department of Geriatric Medicine, Oslo University Hospital, Oslo, Norway. ${ }^{6} \mathrm{HUNT}$ Research Centre, Department of Public Health and Nursing, Faculty of Medicine and Health Sciences, Norwegian University of Science and Technology, (NTNU), Levanger, Norway. ${ }^{7}$ Psychiatric Department, Levanger Hospital, Nord-Trøndelag Hospital Trust, Levanger, Norway. ${ }^{8}$ St. Olavs University Hospital, Sluppen, Trondheim, Norway.

Received: 15 October 2018 Accepted: 24 March 2019

Published online: 18 April 2019

\section{References}

1. Skretting A, Bye EK, Vedøy TF et al. [Rusmidler i Norge 2016] Alcohol and drugs in Norway 2016. Only in Norwegian Norwegian Institute of Public Health 2016 https://wwwfhino/globalassets/dokumenterfiler/rapporter/ rusmidler_i_norge_2016pdf Acessed 19 Feb 2018.

2. Harkonen JT, Makela P. Age, period and cohort analysis of light and binge drinking in Finland, 1968-2008. Alcohol Alcohol. 2011;46(3):349-56.

3. Bjork C, Thygesen LC, Vinther-Larsen M, Gronbaek MN. Time trends in heavy drinking among middle-aged and older adults in Denmark. Alcohol Clin Exp Res. 2008;32(1):120-7.

4. Bratberg GH, C Wilsnack S, Wilsnack R, Havas Haugland S, Krokstad S, Sund $\mathrm{ER}$, Bjorngaard JH. Gender differences and gender convergence in alcohol use over the past three decades (1984-2008), the HUNT study, Norway. BMC Public Health. 2016;16:723.

5. Britton A, Ben-Shlomo Y, Benzeval M, Kuh D, Bell S. Life course trajectories of alcohol consumption in the United Kingdom using longitudinal data from nine cohort studies. BMC Med. 2015;13:47.

6. Geels LM, Vink JM, van Beek JH, Bartels M, Willemsen G, Boomsma DI. Increases in alcohol consumption in women and elderly groups: evidence from an epidemiological study. BMC Public Health. 2013;13:207.

7. Wolf IK, Du Y, Knopf H. Changes in prevalence of psychotropic drug use and alcohol consumption among the elderly in Germany: results of two National Health Interview and examination surveys 1997-99 and 2008-11. BMC Psychiatry. 2017;17(1):90.

8. Grant BF, Chou SP, Saha TD, Pickering RP, Kerridge BT, Ruan WJ, Huang B, Jung J, Zhang $\mathrm{H}$, Fan $\mathrm{A}$, et al. Prevalence of 12-month alcohol use, high-risk drinking, and DSM-IV alcohol use disorder in the United States, 2001-2002 to 2012-2013: results from the National Epidemiologic Survey on alcohol and related conditions. JAMA psychiatry. 2017;74(9):911-23.

9. Han BH, Moore AA, Sherman S, Keyes KM, Palamar JJ. Demographic trends of binge alcohol use and alcohol use disorders among older adults in the United States, 2005-2014. Drug Alcohol Depend. 2017;170:198-207.

10. Krokstad S, Ding D, Grunseit AC, Sund ER, Holmen TL, Rangul V, Bauman A. Multiple lifestyle behaviours and mortality, findings from a large populationbased Norwegian cohort study - the HUNT study. BMC Public Health. 2017; 17(1):58. 
11. Holahan CJ, Schutte KK, Brennan PL, Holahan CK, Moos RH. Episodic heavy drinking and 20-year total mortality among late-life moderate drinkers. Alcohol Clin Exp Res. 2014;38(5):1432-8.

12. Moore AA, Whiteman EJ, Ward KT. Risks of combined alcohol/medication use in older adults. Am J Geriatr Pharmacother. 2007;5(1):64-74.

13. Wadd S, Papadopoulos C. Drinking behaviour and alcohol-related harm amongst older adults: analysis of existing UK datasets. BMC Res Notes. 2014; 7:741.

14. GBD 2016 Alcohol Collaborators. Alcohol use and burden for 195 countries and territories, 1990-2016: a systematic analysis for the Global Burden of Disease Study 2016. Lancet. 2018;392(10152):1015-1035.

15. Gell L, Meier PS, Goyder E. Alcohol consumption among the over 50s: international comparisons. Alcohol Alcohol. 2015;50(1):1-10.

16. Emiliussen J, Nielsen AS, Andersen K. Identifying risk factors for late-onset (50+) alcohol use disorder and heavy drinking: a systematic review. Subst Use Misuse. 2017;52(12):1575-88.

17. Cousins G, Galvin R, Flood M, Kennedy MC, Motterlini N, Henman MC, Kenny RA, Fahey T. Potential for alcohol and drug interactions in older adults: evidence from the Irish longitudinal study on ageing. BMC Geriatr. 2014;14:57.

18. Du Y, Scheidt-Nave C, Knopf H. Use of psychotropic drugs and alcohol among non-institutionalised elderly adults in Germany. Pharmacopsychiatry. 2008;41(6):242-51.

19. Du Y, Wolf IK, Knopf H. Psychotropic drug use and alcohol consumption among older adults in Germany: results of the German health interview and examination survey for adults 2008-2011. BMJ Open. 2016;6(10):e012182.

20. Hajat S, Haines A, Bulpitt C, Fletcher A. Patterns and determinants of alcohol consumption in people aged 75 years and older: results from the MRC trial of assessment and management of older people in the community. Age Ageing. 2004;33(2):170-7

21. Hoeck S, Van Hal G. Unhealthy drinking in the Belgian elderly population: prevalence and associated characteristics. Eur J Pub Health. 2013;23(6):1069-75.

22. Immonen S, Valvanne J, Pitkala KH. The prevalence of potential alcohol-drug interactions in older adults. Scand J Prim Health Care. 2013;31(2):73-8.

23. Moos RH, Schutte K, Brennan P, Moos BS. Ten-year patterns of alcohol consumption and drinking problems among older women and men. Addiction. 2004:99(7):829-38.

24. Leon-Munoz LM, Galan I, Donado-Campos J, Sanchez-Alonso F, LopezGarcia E, Valencia-Martin JL, Guallar-Castillon P, Rodriguez-Artalejo F. Patterns of alcohol consumption in the older population of Spain, 2008 2010. J Acad Nutr Diet. 2015;115(2):213-24.

25. Sacco P, Bucholz KK, Harrington D. Gender differences in stressful life events, social support, perceived stress, and alcohol use among older adults: results from a National Survey. Subst Use Misuse. 2014;49(4):456-65.

26. Reczek C, Pudrovska T, Carr D, Thomeer MB, Umberson D. Marital histories and heavy alcohol use among older adults. J Health Soc Behav. 2016;57(1): 77-96.

27. Kirchner JE, Zubritsky C, Cody M, Coakley E, Chen H, Ware JH, Oslin DW, Sanchez HA, Durai UN, Miles KM, et al. Alcohol consumption among older adults in primary care. J Gen Intern Med. 2007;22(1):92-7.

28. Satre D. Alcohol and drug use problems among older adults. Clin Psychol Sci Pract. 2015:22:238-54

29. Ilomaki J, Paljarvi T, Korhonen MJ, Enlund H, Alderman CP, Kauhanen J, Bell JS. Prevalence of concomitant use of alcohol and sedative-hypnotic drugs in middle and older aged persons: a systematic review. Ann Pharmacother. 2013;47(2):257-68

30. Neutel Cl, Skurtveit S, Berg C. What is the point of guidelines? Benzodiazepine and z-hypnotic use by an elderly population. Sleep Med. 2012;13(7):893-7.

31. Qato DM, Manzoor BS, Lee TA. Drug-alcohol interactions in older U.S. adults. J Am Geriatr Soc. 2015;63(11):2324-31.

32. Nordfjaern T. A population-based cohort study of anxiety, depression, sleep and alcohol outcomes among benzodiazepine and z-hypnotic users. Addict Behav. 2012;37(10):1151-7.

33. Johnell K, Jonasdottir Bergman G, Fastbom J, Danielsson B, Borg N, Salmi P. Psychotropic drugs and the risk of fall injuries, hospitalisations and mortality among older adults. Int J Geriatr Psychiatry. 2017;32(4):414-20.

34. West NA, Severtson SG, Green JL, Dart RC. Trends in abuse and misuse of prescription opioids among older adults. Drug Alcohol Depend. 2015;149: $117-21$.
35. Luijendijk HJ, Tiemeier H, Hofman A, Heeringa J, Stricker BH. Determinants of chronic benzodiazepine use in the elderly: a longitudinal study. $\mathrm{Br} \mathrm{J}$ Clin Pharmacol. 2008:65(4):593-9.

36. Andersen AB, Frydenberg M. Long-term use of zopiclone, zolpidem and zaleplon among Danish elderly and the association with sociodemographic factors and use of other drugs. Pharmacoepidemiol Drug Saf. 2011;20(4):378-85.

37. Gray SL, Eggen AE, Blough D, Buchner D, LaCroix AZ. Benzodiazepine use in older adults enrolled in a health maintenance organization. Am J Geriatr Psychiatry. 2003;11(5):568-76.

38. Ilomaki J, Korhonen MJ, Enlund H, Hartzema AG, Kauhanen J. Risk drinking behavior among psychotropic drug users in an aging Finnish population: the FinDrink study. Alcohol. 2008;42(4):261-7.

39. Stowell KR, Chang CC, Bilt J, Stoehr GP, Ganguli M. Sustained benzodiazepine use in a community sample of older adults. J Am Geriatr Soc. 2008;56(12):2285-91.

40. Jacob L, Rapp MA, Kostev K. Long-term use of benzodiazepines in older patients in Germany: a retrospective analysis. Ther Adv Psychopharmacol. 2017:7(6-7):191-200.

41. Maust DT, Kales HC, Wiechers IR, Blow FC, Olfson M. No end in sight: benzodiazepine use in older adults in the United States. J Am Geriatr Soc. 2016;64(12):2546-53

42. Barnes AJ, Moore AA, Xu H, Ang A, Tallen L, Mirkin M, Ettner SL. Prevalence and correlates of at-risk drinking among older adults: the project SHARE study. J Gen Intern Med. 2010;25(8):840-6.

43. Daatland SO, Slagsvold B. [Vital aldring og samhold mellom generasjoner] Vital aging and solidarity between generations. Only in Norwegian. (NOVA Report 15/2013). Norwegian Institute of Growth, Welfare and Aging 2013. file://C:/Users/kjerstte/Downloads/Vital-aldring\%20og\%20samhold-mellomgenerasjoner-Rapp15-13.pdf. Accessed 19 Feb 2018.

44. Johannessen A, Engedal K, Larsen M, Lillehovde E, Stelander L, Helvik A-S. Alcohol and prescribed drug use among patients admitted to a department of old-age psychiatri in Norway. Nordic Stud Alcohol Drugs. 2017;34(1):5771 http://journals.sagepub.com/doi/pdf/10.1177/1455072516682642. Accessed 19 Feb 2018

45. Li J, Wu B, Selbaek G, Krokstad S, Helvik AS. Factors associated with consumption of alcohol in older adults - a comparison between two cultures, China and Norway: the CLHLS and the HUNT-study. BMC Geriatr. 2017;17(1):172.

46. Nordfjaern T, Brunborg GS. Associations between human values and alcoho consumption among Norwegians in the second half of life. Subst Use Misuse. 2015;50(10):1284-93.

47. The HUNT Study - a longitudinal population health study in Norway. https://www.ntnu.edu/hunt. Accessed 19 Feb 2018.

48. Holmen J, Midtfjell $K$, Krûger $\varnothing$, Langhammer A, Holmen TL, Bratberg GH, Vatten L, Lund-Larsen PG. The Nord-Trøndelag Health Study 1995-97 (HUNT 2): Objectives, contens, methods and participation. Norsk Epidemiologi. 2003;13(1):19-32 https://www.ntnu.no/ojs/index.php/norepid/article/ viewFile/305/283. Accessed 19 Feb 2018.

49. Krokstad S, Langhammer A, Hveem K, Holmen TL, Midthjell K, Stene TR, Bratberg G, Heggland J, Holmen J. Cohort profile: the HUNT study, Norway. Int J Epidemiol. 2013;42(4):968-77.

50. Langhammer A, Krokstad S, Romundstad P, Heggland J, Holmen J. The HUNT study: participation is associated with survival and depends on socioeconomic status, diseases and symptoms. BMC Med Res Methodol. 2012;12:143.

51. Langhammer A, Johnsen R, Holmen J, Gulsvik A, Bjermer L. Cigarette smoking gives more respiratory symptoms among women than among men. The Nord-Trondelag health study (HUNT). J Epidemiol Community Health. 2000;54(12):917-22

52. The Norwegian Prescription Database. www.norpd.no. Accessed 19 Feb 2018.

53. WHO Collaborating Centre for Drug Statistics Methodology, Norwegian Institute of Public Health. https:/www.whocc.no/atc_ddd_index/. Accessed 19 Feb 2018.

54. Hartz I, Tverdal A, Skurtveit S. Langtidsbruk av benzodiazepiner i kombinasjon med opioider og z-hypnotika blant uføretrygdede i Norge. Norsk Farmaceutisk Tidsskrift. 2011:4:24-8 https://admin.farmatid.no/sites/ default/files/pdf_04_2011_24.pdf. Accessed 19 Feb 2018.

55. Nordfjaern T, Bjerkeset O, Bratberg G, Moylan S, Berk M, Grawe R. Sociodemographic, lifestyle and psychological predictors of benzodiazepine and z-hypnotic use patterns. Nord J Psychiatry. 2014;68(2):107-16.

56. Zigmond AS, Snaith RP. The hospital anxiety and depression scale. Acta Psychiatr Scand. 1983;67(6):361-70.

57. Stordal E, Morken G, Mykletun A, Neckelmann D, Dahl AA. Monthly variation in prevalence rates of comorbid depression and anxiety in the general population at 63-65 degrees north: the HUNT study. J Affect Disord. 2008;106(3):273-8. 
58. Helvik AS, Engedal K, Skancke RH, Selbaek G. A psychometric evaluation of the hospital anxiety and depression scale for the medically hospitalized elderly. Nord J Psychiatry. 2011;65(5):338-44.

59. Mykletun A, Stordal E, Dahl AA. Hospital anxiety and depression (HAD) scale: factor structure, item analyses and internal consistency in a large population. Br J Psychiatry. 2001;179:540-4.

60. NIAAA. Understanding the impact of alcohol on human health and wellbeing. Older adults. https:/www.niaaa.nih.gov/alcohol-health/specialpopulations-co-occurring-disorders/older-adults. Accessed 6 Oct 2018.

61. Tevik K, Selbaek G, Engedal K, Seim A, Krokstad S, Helvik AS. Use of alcohol and drugs with addiction potential among older women and men in a population-based study. The Nord-Trondelag Health Study 2006-2008 (HUNT3). PLoS One. 2017;12(9):e0184428.

62. Johannessen A, Helvik AS, Engedal K, Sorlie VM. Older peoples' narratives of use and misuse of alcohol and psychotropic drugs. Scand J Caring Sci. 2016; 30(3):586-93.

63. Wilhelm KA. Men and depression. Aust Fam Physician. 2009;38(3):102-5.

64. Campbell Cl, Weisner C, Leresche L, Ray GT, Saunders K, Sullivan MD, BantaGreen CJ, Merrill JO, Silverberg MJ, Boudreau D, et al. Age and gender trends in long-term opioid analgesic use for noncancer pain. Am J Public Health. 2010;100(12):2541-7.

65. Greenspan JD, Craft RM, LeResche L, Arendt-Nielsen L, Berkley K, Fillingim RB, Gold MS, Holdcroft A, Lautenbacher S, Mayer EA, et al. Studying sex and gender differences in pain and analgesia: a consensus report. Pain. 2007; 132(Suppl 1):S26-45.

66. Xu Y, Schneier F, Heimberg RG, Princisvalle K, Liebowitz MR, Wang S, Blanco C. Gender differences in social anxiety disorder: results from the national epidemiologic sample on alcohol and related conditions. J Anxiety Disord. 2012;26(1):12-9.

67. Gavens L, Goyder E, Hock ES, Harris J, Meier PS. Alcohol consumption after health deterioration in older adults: a mixed-methods study. Public Health. 2016;139:79-87.

68. Crowley K. Sleep and sleep disorders in older adults. Neuropsychol Rev. 2011;21(1):41-53.

69. Abdulla A, Adams N, Bone M, Elliott AM, Gaffin J, Jones D, Knaggs R, Martin D, Sampson L, Schofield P. Guidance on the management of pain in older people. Age Ageing. 2013;42(Suppl 1):i1-57.

70. Johannessen A, Engedal K, Helvik AS. Use and misuse of alcohol and psychotropic drugs among older people: is that an issue when services are planned for and implemented? Scand J Caring Sci. 2015;29(2):325-32.

71. Johannessen A, Helvik A-S, Engedal K, Ulstein I, Sørlie V. Prescribers' of psychotropic drugs experiences and reflections on use and misuse of alcohol and psychotropic drugs among older people: a qualitative study. Qual Prim Care. 2015;23(3):134-40. http://primarycare.imedpub.com/ prescribers-of-psychotropic-drugs-experiencesand-reflections-on-use-andmisuse-of-alcoholand-psychotropic-drugs-among-older-people-aqualitativestudy.pdf. Accessed 19 Feb 2018.

72. Bell HT, Steinsbekk A, Granas AG. Factors influencing prescribing of fall-riskincreasing drugs to the elderly: a qualitative study. Scand J Prim Health Care. 2015;33(2):107-14.

73. Dixon MA, Chartier KG. Alcohol use patterns among urban and rural residents: demographic and social influences. Alcohol Res. 2016;38(1):69-77.

74. NIAAA. Alcohol alert. National Institute on Alcohol Abuse and Alcoholism Publication Distribution. January 2007, Number 71. https://pubs.niaaa.nih. gov/publications/aa71/AA71.pdf. Accessed 19 Feb 2018.

75. Rose JE, Brauer LH, Behm FM, Cramblett M, Calkins K, Lawhon D. Psychopharmacological interactions between nicotine and ethanol. Nicotine Tob Res. 2004;6(1):133-44.

76. Desai HD, Seabolt J, Jann MW. Smoking in patients receiving psychotropic medications: a pharmacokinetic perspective. CNS drugs. 2001;15(6):469-94.

77. Shi Y, Hooten WM, Warner DO. Effects of smoking cessation on pain in older adults. Nicotine tob Res. 2011;13(10):919-25.

78. Skurtveit S, Furu K, Bramness JG, Tverdal A. Benzodiazepine use in all alcohol consumers predicts use of opioids in patients 20 years later--a follow-up study of 13,390 men and women aged 40-42 years. Pharmacoepidemiol Drug Saf. 2008;17(9):926-33.

79. Breslow RA, Dong C, White A. Prevalence of alcohol-interactive prescription medication use among current drinkers: United States, 1999 to 2010. Alcohol Clin Exp Res. 2015;39(2):371-9.

\section{Ready to submit your research? Choose BMC and benefit from:}

- fast, convenient online submission

- thorough peer review by experienced researchers in your field

- rapid publication on acceptance

- support for research data, including large and complex data types

- gold Open Access which fosters wider collaboration and increased citations

- maximum visibility for your research: over $100 \mathrm{M}$ website views per year

At BMC, research is always in progress.

Learn more biomedcentral.com/submissions 